\title{
Kentsel Ulaşım Sınıflamasında Yayalaştırılmış Cadde ve Sokak Uygulamalarının Başarı Değerlendirilmesi: Kırklareli İli Lüleburgaz İlçesi Örneği
}

\author{
Oğuz Ateş ${ }^{1 *}$, Fürüzan Aslan ${ }^{2}$, Engin Kabataş ${ }^{3}$, Nehar Büyükbayraktar $^{4}$ \\ ${ }^{1}$ Kırklareli Üniversitesi, Mimarlık Fakültesi, Peyzaj Mimarlı̆̆ı Bölümü, Kırklareli, Türkiye (ORCID: 0000-0002-5395-0355), oguzates@klu.edu.tr \\ ${ }^{2}$ Kırklareli Üniversitesi, Mimarlık Fakültesi, Peyzaj Mimarlığı Bölümü, Kırklareli, Türkiye (ORCID: 0000-0001-7981-8777), a.furuzan@klu.edu.tr \\ ${ }^{3}$ Kırklareli Üniversitesi, Mimarlık Fakültesi, Peyzaj Mimarlığı Bölümü, Kırklareli, Türkiye (ORCID: 0000-0002-3191-5866), kabatasengin005@ gmail.com \\ ${ }^{4}$ Kırklareli Üniversitesi, Mimarlık Fakültesi, Peyzaj Mimarlığı Bölümü, Kırklareli, Türkiye (ORCID: 0000-0001-6582-9221), neharbykbyrktr@ gmail.com
}

(İlk Geliş Tarihi 26 Eylül 2021 ve Kabul Tarihi 16 Aralık 2021)

(DOI: 10.31590/ejosat.1000961)

ATIF/REFERENCE: Ates, O., Aslan, F., Kabataş, E. \& Büyükbayraktar, N. (2021). Kentsel Ulaşım Sınıflamasında Yayalaştırılmış Cadde ve Sokak Uygulamalarının Başarı Değerlendirilmesi: Kırklareli İli Lüleburgaz İlçesi Örneği. Avrupa Bilim ve Teknoloji Dergisi, (31), 382-389.

$\ddot{O} \mathbf{z}$

Yayalaştırma kavramı tanım olarak, kentsel yolların yalnız yürünebilen yerlere dönüştürülmesi veya yapılacak çeşitli düzenlemeler ile yürüyenlere daha geniş alanlar ayrılması olarak ifade edilmektedir. Başarılı bir yayalaştırılmış alanın kentte yaşayanlara sağladığı sosyal, psikolojik ve ekonomik pek çok faydası bulunmaktadır. Bu çalışmada Kırklareli İli Lüleburgaz ilçe merkezinde yer alan yayalaştırılmış sokakların başarı değerlendirmesi yapılmıştır. Yayalaştırılmış bölge, erişim ve bağlantılar, arazi kullanımı ve fonksiyonel dağılım, mekânsal kalite, konfor, imaj ve peyzaj, kullanım zamanı, sosyal yaşam başlıkları altında değerlendirilmiştir. Değerlendirme sonucunda, özel tasarlanmış satış birimleri hariç tüm şartları karşıladığı görülmüşsür. Aynı yöntemle değerlendirilen diğer yayalaştırılmış alanlarla karşılaştırmalar yapılmıştır. Son bölümde ise çalışma alanına ait görüş ve önerilere yer verilmiştir.

\section{Success Evaluation of Pedestrianized Streets and Street Applications in Urban Transportation Classification: The Case of Lüleburgaz / Kirklareli / Turkey}

\begin{abstract}
The term of pedestrianization is defined as the transformation of urban roads into places that can be walked alone or to separate larger areas for walkers with various arrangements to be made. A successful pedestrianized area has many social, psychological and economic benefits for city dwellers. In this study, the success assessment of the pedestrianized streets in Lüleburgaz district center of Kirklareli Province was made. Pedestrianized area has been evaluated under the headings, access and connections, land use and functional distribution, spatial quality, comfort, image and landscape, time of use, social life. As a result of the evaluation, it has been seen that it meets all the conditions except for specially designed sales units. Comparisons with other pedestrianized areas evaluated with the same method were made. In the last section, opinions and suggestions related to the field of study are included.
\end{abstract}

Keywords: Pedestrianization, Success Evaluation, Lüleburgaz.

* Sorumlu Yazar: oguzates@klu.edu.tr 


\section{Giriş}

Tarihi, insanlığın topluluk olamaya başladı̆̆ı dönemlere kadar uzanan yollar, ulaştırma faaliyetlerinin sağlanmasına temel oluşturan kentsel fonksiyonlardan biri ve bir kenti tanımlayan önemli bir elemandır. Yol mekânının ilk örnekleri olan patikalar, insan hareketliliği, ilişkiler ve haberleşme gereksinimleri ile ortaya çıkmıştır. M.Ö. 3000 - 4000 yıllarında Mısır'da Nil Nehri boyunca yollar düzenlenmiş, bu yollarda iklimsel verilerden korunmaya yarayan elemanlar ve döşemeler yapılmıştır. Babil'de M.Ö. 600 yıllarında $60 \mathrm{~cm}$ genişliğinde dar sokaklara yer verilmiş, Yunan uygarlıklarında ise yaya yolları özellikle eğimli alanlarda kullanılmıştır (Giritlioğlu, 1991; Gültiken, 2010).

Millet kentinde yaya yolu ve taşıt yolunda farklı döşemelerin kullanıldığı, yaya yollarının $1.65 \mathrm{~m}$ ve taşıt yollarının $3.5 \mathrm{~m}$ geniş̧liğinde düzenlendiği görülmüştür. Roma'da ise "düz yol, en kısa yoldur" prensibi benimsenerek, dik ve diyagonal kesişen yollar yapılmıştır. M.Ö. 1000 yılında Pompei şehrinde ise yaya ve taşı yolu ayrımı gözlemlenmektedir. İnsanlığın yerleşik hayata geçmesinden sonra basit bir hesapla 9600 yıl boyunca insanlar ulaşımını büyük ölçüde yürüyerek gerçekleştirdiği görülmektedir. Bu nedenle kentler, daha insan ölçeğinde gelişmeler göstermişlerdir (Vuchic, 1999).

Ortaçağ dönemlerine bakıldığında, ilk etapta oturma işlevinin uzantısı olarak düşünülen yollar, sonraki dönemlerde çalışma işlevlerini de kapsamıştır. Gelişen ticaret ile paralel olarak yollar da gelişmeye başlamış, Rönesans ve Barok dönemlerindeki farklı akımlarla, kent dokusu içerisinde farklı işlev fonksiyonlar gelişmiştir.19. yy' da kullanılan bisiklet ve tramvay, 20. yy' a gelindiğinde yerini otomobillere birakmaya başlamıştır. Otomobilin kullanılmasıyla yol sisteminin kentlerdeki değişimi başlamıştır (Gehl, Gemzøe, Kirknæs, ve Sternhagen Søndergaard, 2006).

İlk olarak cadde ve sokakların yaya alanlarına dönüştürülmesi 1926'da Almanya'nın Essen şehrindeki Limbecker Strase de gerçekleştirilmiştir. Tarihi kent merkezlerindeki dar alışveriş caddelerinden oluşan trafik sıkışıklıklarını önlemek amacıyla ortaya çıkan yayalaştırma, 2. Dünya savaşından sonra yaygınlaşmış, 1969 yılında sayısı 63'e ulaşmıştır. 1973 yılında ortaya çıkan petrol krizi ile yayalaştırma ve toplu taşıma uygulamalarına hız verilmiş, pek çok kentte uygulanmaya başlamıştır. Bu dönemde yapılan çalışmalar sosyal açıdan değerlendirilmiş ve çalışmalar bu yöne yoğunlaştırılmıştır. $\mathrm{Bu}$ dönemde Almanya Münih kentinde yapılan yayalaştırma çalışması buna en iyi örnektir ve bu çalışma sonrası Almanya'ya bir model oluşturulmuştur (Robertson, 1994).

Avrupa'da özellikle 1960'lı yıllardan sonra hızla artış gösteren otomobil sayısı, plancıları yeni önlemler geliştirmeye yönlendirmiştir. 1960'lı yıllarda bile birçok Avrupa şehrinde trafik sıkışıklıkları gözlemlenmiştir. $\mathrm{Bu}$ problemle başa çıkabilmek için, otomobil kullanımının önüne geçen diğer ulaşım sistemlerine ağırlık verilmiştir. Bu sayede, trafiğe kapalı, yayalaştırılmış bölgeler büyük alanlara yayılmış ve ticari alanlara dönüşmüştür (Vuchic, 1999).

Günümüzde insanlar, kendinden önceki kuşaklara göre daha az yürümektedir. Buna neden olarak kişisel otomobillerin artması, tembelleşme veya yürümeyi konforsuz bulmaları gösterilebilir (Robertson, 1994).

e-ISSN: 2148-2683
Yayalar bir kentte yaşayanların büyük çoğunluğunu kapsayan ve toplumun her kesiminden insanları bünyesinde barındıran bir kitledir. Yayalar, içerisinde bebekler, çocuklar, hamileler, yaşlılar ve engelliler bulunan bir topluluktur. Yaya hareketleri yaya dış hareketleri, dinamik yaya hareketleri ve statik yaya hareketleri olarak 3 ana başlikta incelenebilir (Rapaport, 1987).

Yayalaştırma kavramı tanım olarak, kentsel yolların yalnız yürünebilen yerlere dönüştürülmesi veya yapılacak çeşitli düzenlemeler ile yürüyenlere daha geniş alanlar ayrılması olarak ifade edilmektedir (Keleş, 2021).

Yayalaştırma kavramı incelenirken, sadece taşıta yasaklanmış yaya yolları algılanmamalı, yaya hareketleri ve aktivitelerinin dikkatlice gözlemlendiği, insani ögeleri ön plana çıkaran ve taşıtların kontrollü hareketinin sağlandığı bir sistem algılanmalıdır. Araç trafiğini tamamen ortadan kaldırmadan, hız azaltıcı tasarımlar oluşturarak, sınırlamalar getirerek ya da caydırıcı fiyat politikaları uygulayarak da yaya öncelikli bir sistem kurgulanabilir (Brambilla ve Longo, 1978).

Kent merkezlerinde her geçen gün artan nüfus yoğunluğu ve taşıt trafiği, yayalaştırma isteğini arttırmakta olsa da yayalaştırma nedenleri ülkeden ülkeye farklılaşmaktadır. Hızlı kentleşmeyi, değişen yaşam koşullarını, teknolojik gelişmeleri ve toplum yapısını birlikte düşündüğümüzde, toplumun, kent içinde trafik ve yapılar arasında kaldığı görülmektedir. Bu da yayalaştırılmış alanlara olan talebi arttırmakta ve tüm dünyada kent merkezlerinin trafikten arındırılıp yaya mekânlarına dönüşmesine neden olmaktadır. Yayalaştırma sebepleri incelendiğinde, tarihi binaların ve kent dokusunun korunması, ticaretin arttırılması, konut alanlarının iyileştirilmesi, çevrenin güzelleştirilmesi ve sosyal hayatın canlandırılması ön plana çıkmaktadır (Moudon, 1987).

Tamamen yayalaştırılmış bir mekânın başarısının sağlanmasının en önemli kriterlerinden birisi, kullanıcıları çekebilecek aktivitelere yoğun olarak yer verilmesidir. Ayrıca yer seçiminde, ticaret alanlarına yakın olması, tarihi bir merkez barındırması, çevresinde üniversite benzeri yoğun kullanıcı sayısına sahip mekânların bulunması önemli etkenlerdir (Rubenstein, 1992).

$\mathrm{Bu}$ anlamda yayalaştırılmış alanların başarısının ölçülmesi gerekliliği ortaya çıkmaktadır.

Bu çalışmada Kırklareli İli Lüleburgaz ilçesinde yer alan yayalaştırılmış caddeler başarı ölçütleri kapsamında değerlendirilmiştir. Dünya'da ve ülkemizdeki diğer yayalaştırılmış caddelerle karşılaştırması yapılmıştır.

\section{Materyal ve Metot}

Çalışmanın materyalini Kırklareli ili Lüleburgaz ilçesi İstanbul caddesi, Stad caddesi, Fatih Caddesi, Şevket Özdül Caddesi, Turgutbey Caddesi, Orhan Özcanlar Sokak, Hal Sokak, Fındıklı Sokak, Açık Çeşme Sokak ve Fetfane sokağın içinde bulunduğu yayalaştırılmış bölge oluşturmaktadır (Şekil 1). 


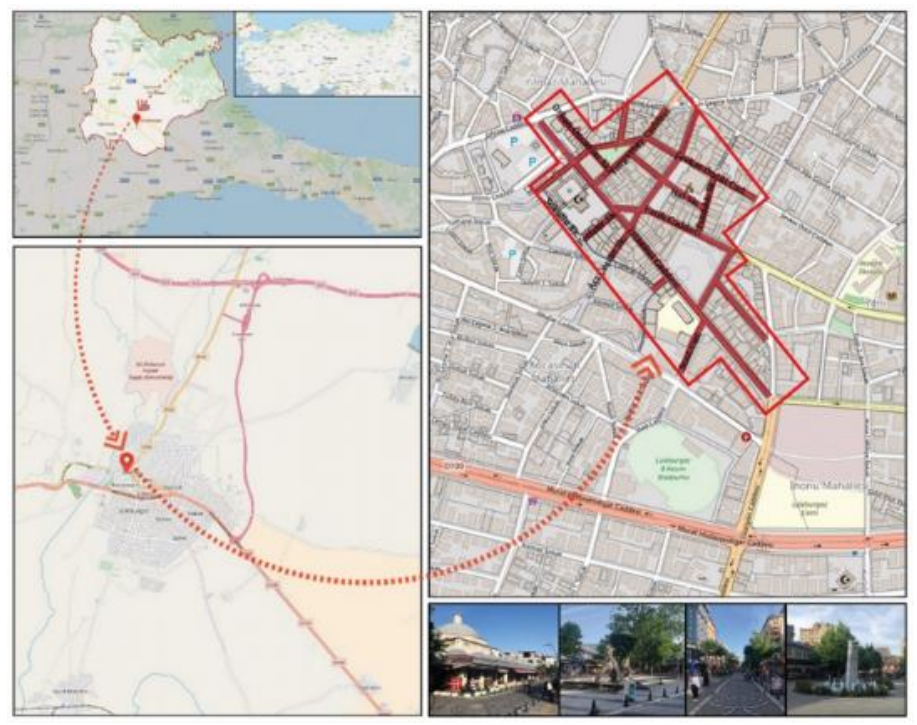

Şekil 1. Çalışma alanının konumu.

Yöntemin ilk bölümünde, literatür taraması yapılmıştır. Yayalaştırılmış alanların tarihsel süreci, yayalaştırma biçimleri ve dünyadaki uygulamalar incelenmiştir. İkinci aşamada ise çalışma alanına ait analizler yapılmış, Gültiken (2010) tarafından ortaya konan başarı ölçütleri açısından çalışma alanı incelenmiştir. Başarı ölçütleri ile incelenmiş diğer caddeler çalışma alanı bulguları ile karşıllaştırılmış ve önerilerde bulunulmuştur (Şekil 2).

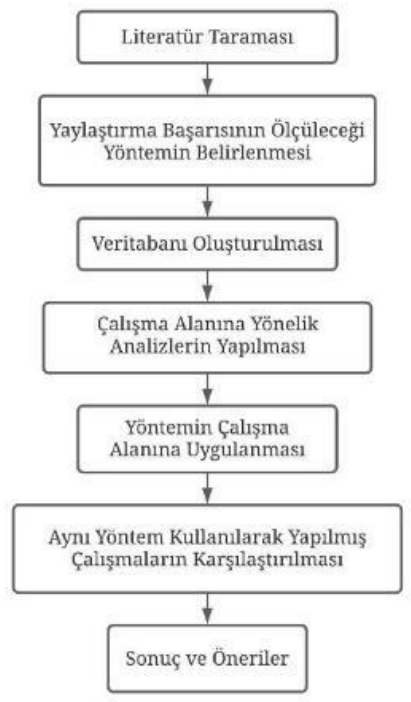

\section{Şekil 2. Yöntem Akış Şeması}

Gültiken (2010) tarafından; günümüzde yayalaştırma uygulamalarının başarıya ulaşması için uyulması gereken ölçütler, son dönemde gelişen literatür sentezi sonucunda;

- Erişim ve Bağlantılar

- Arazi kullanımı ve Fonksiyonel Dağılım

- Mekânsal Kalite-Konfor-İmaj ve Peyzaj

- Kullanım Zamanı

- Sosyal Yaşam

olarak ortaya konulmuştur.

\section{Araştırma Sonuçları ve Tartışma}

Çalışma alanı materyal ve metot bölümünde detayları verilen yönteme göre değerlendirilmiştir. Erişim ve bağlantılar, arazi kullanımı ve fonksiyonel dağılım, mekânsal kalite - konfor - imaj ve peyzaj, kullanım zamanı ve sosyal yaşam olmak üzere 5 ana başlıkta açıklanacaktır.

\subsection{Erişim \& Bağlantılar}

Özmen ve Kayacan (2021) kentsel çevreden kaynaklı stress faktörlerine, kalabalık, etrafa dağılmış çöpler, yüksek katlı yapılaşma, trafik, kazalar ve yeşilalanların varlığı ve ulaşılabilirliği örnek olarak verilebilir demiştir. Bu bağlamda kentsel mekânlarda yaşayanların stress düzeylerini azaltmak için de erişim ve bağlantılar başlığı önem arz etmektedir.

Lüleburgaz ilçesinin tarihi kent çekirdeğini oluşturan çalışma alanı ve yakın çevresi Murat Hüdavendigar (D100), İstasyon, İstanbul, (D565), Fatih ve Turgutbey gibi önemli karayolları ile dolmuş güzergâhları arasında yer almaktadır.

Çalışma alanına erişim özel/ticari araçlar, dolmuşlar ve bisikletler aracılığıyla sağlanmaktadır. Yayalaştırılmış bu bölge üzerinde çok sayıda resmi kurum, banka ve ticari faaliyetler sürdürüldüğü için alana yakın bölgelerde trafik yoğunluğu oldukça fazladır. Ayrıca bu bölge çevresindeki yollar tek yön olarak planlanmış ve bu sayede bir nebze de olsa trafik yoğunluğunun önüne geçilmeye çalışılmıştır.

Yayalaştırılmış bölgelerde trafik yoğunluğunun önüne geçmek, bu alanlarda özel araç kullanımını engellemek amaciyla; İstanbul, Fatih ve Turgutbey caddeleri ile Fetfane, Orhan Özcan, Şevket Ödül Acı Çeşme sokaklarının giriş/çıkış kısımlarında bariyer sistemleri kullanılmaktadır. Yayalaştırılmış bölge ve yakın çevresinde 3'ü açık, 1'i kapalı olmak üzere 4 otopark mevcuttur. Alan içerisinde 4 adet taksi ve 1 adet elektrikli taksi durağı yer almaktadır (Şekil 3).

Yine çalışma alanı içerisindeki alanlara erişim kolaydır. Karmaşıklık içermeyen bağlantılar ile ve evrensel tasarım ilkeleri doğrultusunda incelendiğinde, tüm bireylerin kamusal mekânlara erişilebilirliğinin mümkün olduğu tespit edilmiştir. $\mathrm{Bu}$ bağlamda da pek çok gereksinimi sağlamaktadır.

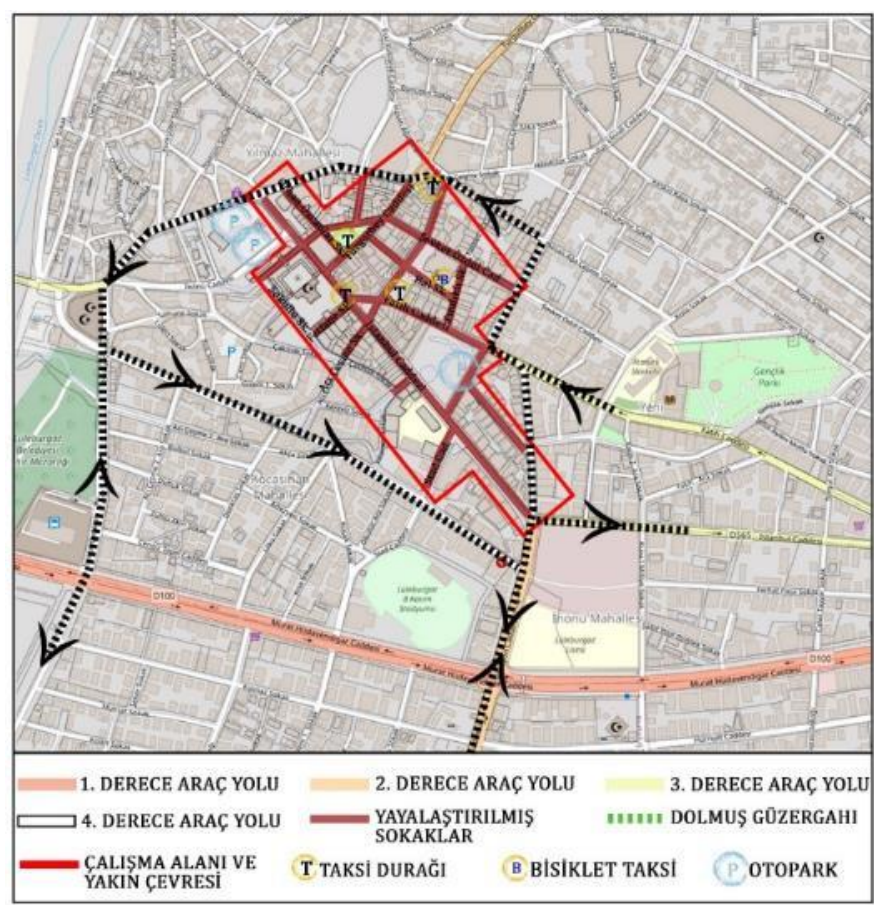

Şekil 3. Erişim - Bağlantılar Analizi 


\subsection{Arazi Kullanımı Dokusu \& Fonksiyonel Dağılım}

Lüleburgaz'daki yayalaştırma bölgesinde yayalaştırma öncesi, özellikle bu bölgede ticaret ile uğraşan işyeri sahipleri, insanların buralara erişimin zorlaşacağı nedeniyle yayalaştırmaya karşı çıkmışlardır. Fakat yayalaştırma çalışması sonrası özellikle perakende ticarette yaşanan artış ve sosyal çevredeki değişim herkesi memnun etmiştir.

Yayalaştırılmış bölge ve yakın çevresinde eğitim tesis alanları, resmi kurumlar, ticaret alanları ve tarihi Sokullu Mehmet Paşa Külliyesi yer almaktadır. Kent çekirdeğini yayalaştırma hedefiyle başlanan yayalaştırma çalışmasının yapıldığ 1 bölgede ticari faaliyetler ön planda yer alıp, kentte yaşayan bireylerin gerek temel gerek sosyo-külürel gerekse rekreasyonel tüm ihtiyaçlarını karşılayacak fonksiyonları barındırmaktadır.

İstanbul Caddesi ile Turgutbey Caddesi üzerinde yoğun olarak giyim, elektronik, telekomünikasyon, yeme-içme mekânları ve çeşitli ofisler yer alıyorken, Orhan Özcan sokakta yeme içme faaliyetleri, Şevket Ödül Cadde üzerinde giyim sektörü yoğunluk göstermektedir.

Ayrıca çalışma alanı içerisinde yer alan meydanlar kentlilerin buluşma noktaları olup bu alanlarda oturma dinlenme gibi çeşitli rekreasyon aktiviteleri ile sosyo-kültürel etkinlikler gerçekleştirilmektedir (Şekil 4).

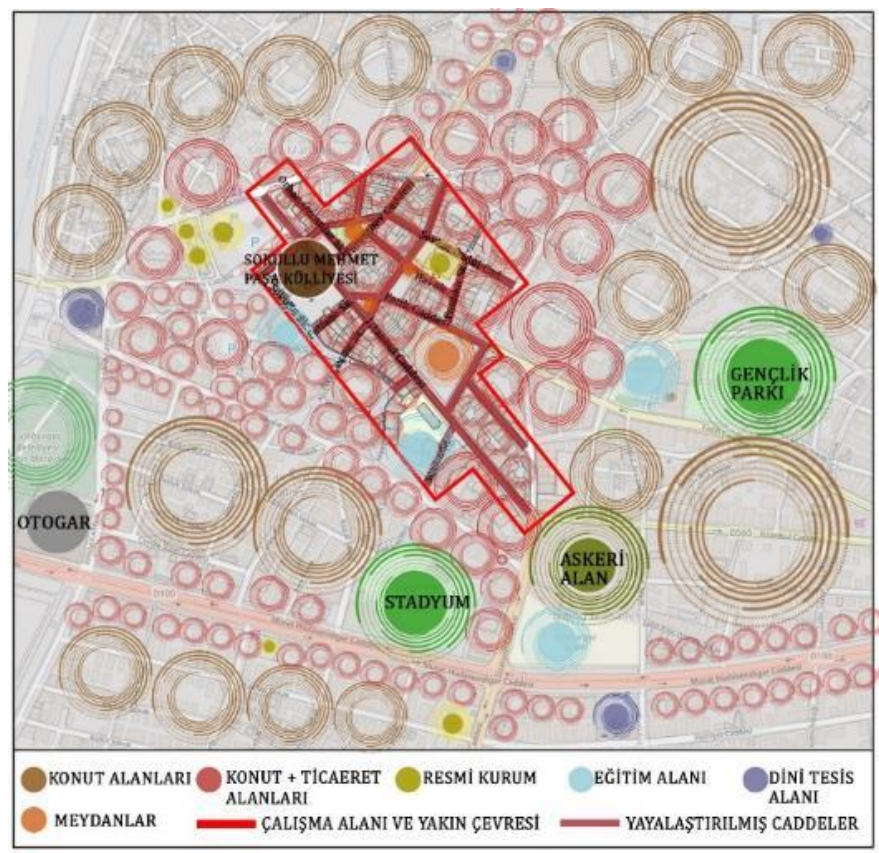

Şekil 4. Alan Kullanım Fonksiyonları.

Çalışma alanı üzerinde yer alan ve çoğunluğu ticari fonksiyona sahip binalar genel olarak İstanbul Caddesi üzerinde 3 ve 5 katll, Turgutbey caddesinde 3 ve 4 katll, Şevket Ödül Caddesinde 4 ve 5 katlı, Fatih Caddesinde 3 ve 5 katlı, Orhan Özcanlar sokak üzerinde 4 katlı binalar yoğunluk göstermektedir.

Yayalaştırılmış bölge üzerinde yer alan bu binaların zemin katları genelde yeme-içme, giyim, telekomünikasyon gibi amaçlara hizmet etmekte olup, üst katların daha çok ofis amaçlı kullanıldıkları tespit edilmiştir (Şekil 5).

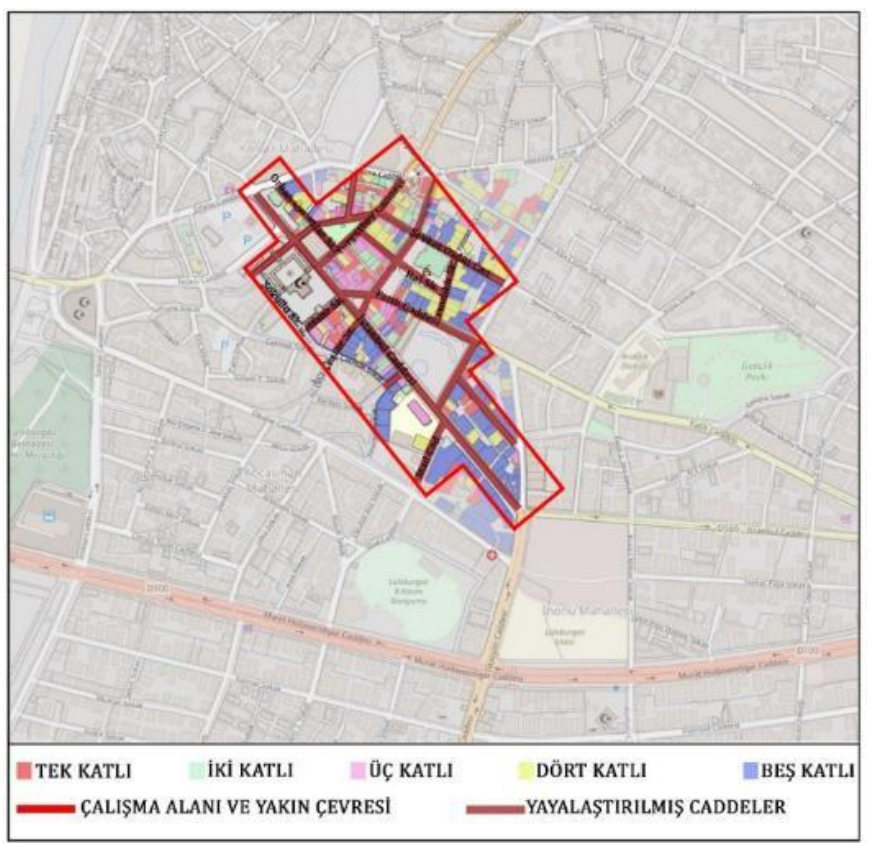

Şekil 5. Kat Yüksekliği Analizi.

\subsection{Mekânsal Kalite \& Konfor \& İmaj \& Peyzaj}

Gehl ve ark. (2006) yaptıkları araştırmada iki başlığa özellikle dikkat çekmişlerdir. Kent içerieisndeki kamusal bir mekânın kullanıcılar tarafından tercih edilebilmesinde ilk olarak insan ölçeğinde, iklimsel ve estetik değerlere sahip olması ve ikinci olarak ise hem trafik hem de güvenlik olarak korunmuş olması oldukça önemli bir yer tutmaktadır. Bu bağlamda çalışma alanına yönelik ilk etapta imaj analizi yapılmıştır.

Yayalaştırılmış bölge, her yaştan kullanıcının ihtiyacını karşılayacak nitelikleri barındırması, kişileri bir araya getirerek buluşma noktası görevi görmesi ve kişilerin bir araya gereke çeşitli etkinlikleri gerçekleştirme imkânı sunması nedeniyle ilçenin gece-gündüz en hareketli ve kalabalık noktasıdır.

Konfor ölçütlerinden birisi olan güvenlik, kullanım zamanı ve kullanıcını yoğunluğunu etkilemese de öncelikli tehdit olduğu ortadadır. Mekânsal kullanımın çeşitliliği alanın daha ilgi çekici bir hal almasına önemli katkı sağlamıştır. $\mathrm{Bu}$ kapsamda güvenliği sağlamak ve kişilerin alanda kendilerini güvende hissedebilmesi amaciyla emniyet güçleri alanda sürekli devriye atmakta ve kongre meydanında polis ekibi nöbet tutmaktadır. Ayrıca alanın çeşitli yerlerinde mobese kameraları yer almaktadır. $\mathrm{Bu}$ anlamda bu mekânın tercih edilebilirliğinde suçun varlığının düşük olması önemli bir belirleyici olarak öne çıkmamaktadır.

Ağaçlandırılmış caddeler ve gelişmiş büyük yol ağaçları alanda mikro klima etkisi yaratarak yayaların konforlu bir şekilde faaliyetlerini gerçekleştirmelerine olanak sunmaktadır. Ayrıca meydanlarda çeşitli amaçlarla su ögesinin kullanılması, ilgi çekici gece aydınlatmaları, modern oturma alanlarının ve ilgi çekici bitkisel tasarım çalışmaların varlığı bu bölgelerin mekânsal kalitesini arttıran önemli özellikleridir.

Ancak kalite ve konfor açısından oturma banklarının halen yeterli olmadığı başarı değerlendirmesi açısında başarılı bulunmamaktadır. Cadde de çok az sayıda sanat objeleri kullanılmıştır. Caddenin tarihsel yapısı sanat objelerinin önüne geçmektedir. Bu nedenle tarihi binaların bakımı önemlidir. Tarihi 
binaları zemin katlarında bulunan ticarethanelerin değişik renkteki tente ve tabelaları adeta bir karmaşa oluşturmaktadır.

Çalışma alanında üzerinde güvenlik ve ayakkabı boyacılarına yönelik tasarlanmış kabinler yer almasına rağmen, satış birimlerine yönelik donatılar yer almamaktadır (Çizelge 1).

Çizelge 1. Çalışma alanına ait doğal ve yapılı çevre peyzaj elemanları.

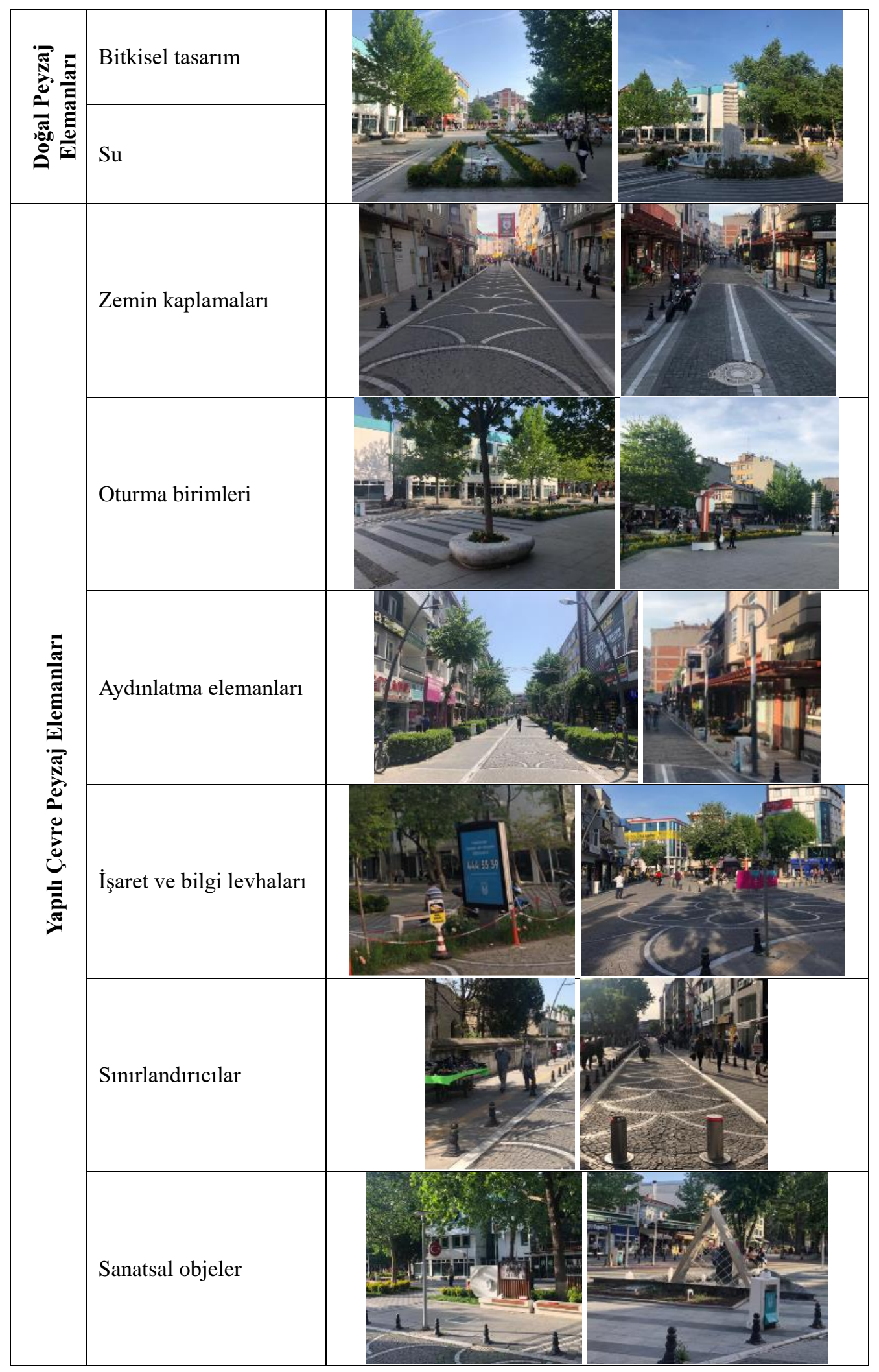




\subsection{Kullanım Zamanı}

Tarihi kent merkezi niteliği taşıyan bu alan sahip olduğu özellikleri nedeniyle gece-gündüz her yaştan kullanıcının dikkatini çekmektedir. Özellikle yayalaştırılmış bölge üzerinde yer alan yeme içme alanlarının varlığı sahip olduğu tarihi dokuyu ön plana çıkaran tasarım yaklaşımı ile birlikte yayaların geç saatlere kadar bu alanı kullanmalarına olanak tanımaktadır.

\subsection{Sosyal Yaşam}

Alan üzerinde yer alan meydanlarda çeşitli özel günlerde (23 Nisan, 19 Mayıs, Lüleburgaz'ın kurtuluşu) etkinlik ve konserler düzenlenmektedir. Ayrıca pandemi dönemi öncesi Zübeyde Hanım parkının bulunduğu bölgede geleneksel olarak düzenlenen farklı temalar üzerine konuşmacıların getirildiği “Çınaraltı Sohbetleri” gerçekleştirilmiştir. Lüleburgaz'da açık havada yapılacak çeşitli sergi, kutlama ve etkinlikler bu alanlarda gerçekleştirilmektedir.

Yayalaştırılmış bölgede çok sayıda seyyar satıcı yer almaktadır. Satışı yapılan ürünlerin birçoğu yerel üreticilerin köylerinde üretmiş olduğu ürünlerden oluşmaktadır. Fakat alan üzerinde bu ürünlerin satışlarının yapılabileceği satış birimleri bulunmamaktadır.

\subsection{Başarı Ölçütlerinin Değerlendirilmesi}

Tüm analizlerin ardından Çizelge 2'de gösterildiği üzere başarı ölçütleri değerlendirilmiştir.

Çizelge 2. Çalışma Alanına Ait Başarı Ölçütleri

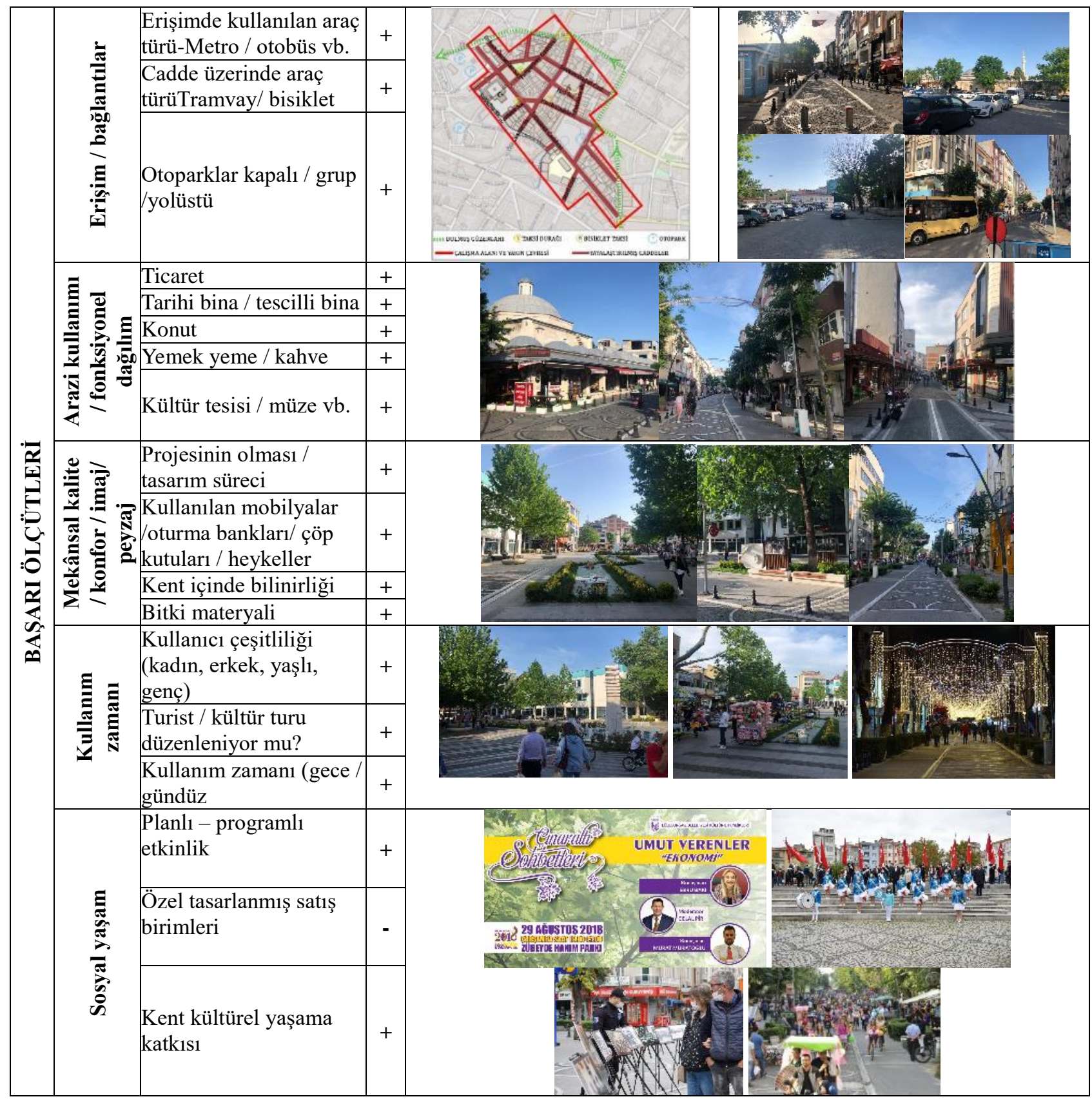




\section{7. Çalışma Alanı ile Diğer Yayalaştırılmış Caddelerin Karşılaş̧tırılması}

Aynı yöntemin uygulandığı yayalaştırılmış caddeler ile Lüleburgaz ilçesi yayalaştırılmış caddeleri karşılaştırılmıştır. Gültekin (2010) tarafından hem yurtiçindeki hem yurtdışındaki incelenen örneklere çalışma alanı da eklenmiş ve sonuçlar karşılaştırılmıştır. Karşılaştırma sonucunda Lüleburgaz yayalaştırma bölgesinin "Özel Satış Birimleri” başlığı dışındaki tüm şartları sağladığı görülmüştür. Yayalaştırma çalışmasının başarısını gösteren bu karşıllaştırma ile çalışma alanına ait getirilebilecek öneriler de ortaya çıkmıştır. Bu bağlamda çalışma alanının kullanıcılar tarafından yoğun kullanılma sebeplerinden birisinin bu olduğu düşünülmektedir.

Çizelge 3. Aynı Yöntemle Yapılmış Diğer Yaya Mekanları ile Çalışma Alanının Karşılaştırılması (Gültiken, 2010'den değiştirilerek).

\begin{tabular}{|c|c|c|c|c|c|c|c|c|c|c|c|c|c|c|c|c|c|c|}
\hline & \multicolumn{3}{|c|}{$\begin{array}{c}\text { Erişim - } \\
\text { Bağlantılar }\end{array}$} & \multicolumn{5}{|c|}{ Arazi Kullanımı } & \multicolumn{4}{|c|}{ Mekansal Kalite } & \multicolumn{3}{|c|}{ Kullanım Zamanı } & \multicolumn{3}{|c|}{ Sosyal Yaşam } \\
\hline & 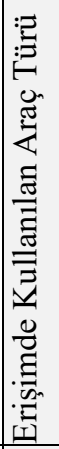 & 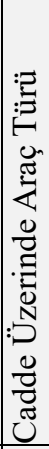 & 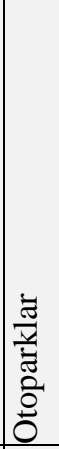 & 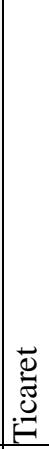 & 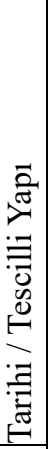 & 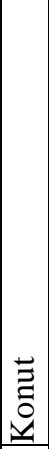 & 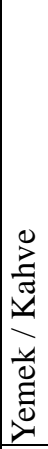 & 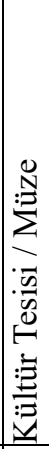 & 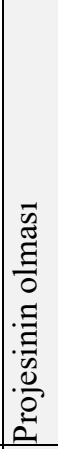 & 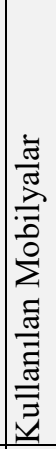 & 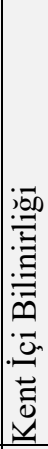 & 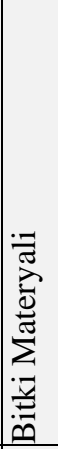 & 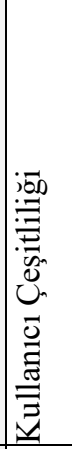 & 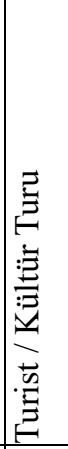 & 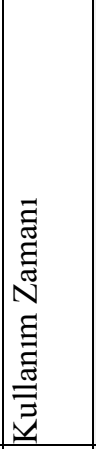 & 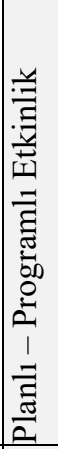 & 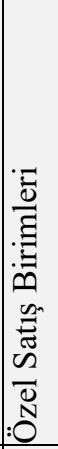 & 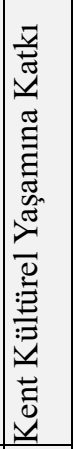 \\
\hline Strasburg, Fransa & + & + & + & + & + & + & + & + & + & + & + & $\mathrm{X}$ & + & + & + & + & $\mathrm{X}$ & $\mathrm{X}$ \\
\hline Münih, Almanya & + & + & + & + & + & + & + & + & + & + & + & - & + & + & + & + & $\mathrm{X}$ & + \\
\hline Woonerf, Hollanda & + & + & + & + & $\mathrm{X}$ & + & + & $\mathrm{X}$ & + & $\mathrm{X}$ & + & $\mathrm{X}$ & + & + & + & + & + & + \\
\hline Piazza Del Cambo, Siena, İtalya & + & - & $\mathrm{X}$ & + & + & - & $\mathrm{X}$ & + & + & + & + & - & + & + & + & + & + & + \\
\hline Asahikawa, Japonya & + & $\mathrm{X}$ & + & + & - & $\mathrm{X}$ & + & $\mathrm{X}$ & + & $\mathrm{x}$ & + & $\mathrm{X}$ & + & - & + & + & + & + \\
\hline Santa Monica Place, ABD & + & - & + & + & - & - & + & - & + & $\mathrm{X}$ & + & - & + & $\mathrm{X}$ & + & + & + & + \\
\hline Minesota, Mineapolis, ABD & + & - & + & + & - & - & + & - & + & $\mathrm{X}$ & + & - & + & $\mathrm{X}$ & + & + & + & + \\
\hline New York, ABD & + & + & + & + & - & + & + & + & + & + & + & $\mathrm{X}$ & + & $\mathrm{X}$ & + & $\mathrm{X}$ & + & + \\
\hline La Rambla, İspanya & + & - & + & + & + & + & + & + & + & + & + & $\mathrm{X}$ & + & + & + & + & + & + \\
\hline İstiklal Caddesi, Türkiye & + & + & + & + & + & $\mathrm{X}$ & + & + & + & $\mathrm{X}$ & + & $\mathrm{X}$ & + & + & + & + & + & + \\
\hline Lüleburgaz, Türkiye & + & + & + & + & + & + & + & + & + & + & + & + & + & + & + & + & - & + \\
\hline
\end{tabular}

\section{Sonuç}

Tüm dünyada yaya alanlarının sayısı her geçen gün artsa da yayalaştırma sebepleri ülkeden ülkeye değişmektedir. Yayalaştırmanın amaçları arasında çevreyi koruma, konut çevresi ve yaya ilişkilerini güçlendirme, boş zamanları değerlendirme, toplumsal ve ekonomik amaçlar bulunmaktadır. Lüleburgaz ilçesinde bulunan çalışma alanımızın tüm bu amaçları karşıladığı görülmektedir.

Tüm Dünyada olduğu gibi Lüleburgaz ilçesinde de günden güne artan taşıt trafiği sonucu yaya kaldırımları yetmemekte, özellikle kent merkezinde trafik sıkışıklığ 1 meydana gelmektedir. $\mathrm{Bu}$ bağlamda kent merkezinin yayalaştırılması, yaya trafiğini rahatlatmış, kent merkezindeki trafik sıkışıklığını azaltmış, ticaret alanlarının satış miktarını arttırmıştır.

Yayalaştırma çalışması başarı ölçütleri bakımından irdelendiğinde ise sadece "Özel Tasarım Satış Birimleri” başlığı altında yetersiz olduğu görülmektedir. Çalışma alanı genelinde çok sayıda seyyar satıcı bulunmasına ve bu satıcıların pek çoğunun yöresel, el yapımı ürünler satmasına rağmen, bu satışların daha düzenli yapılabileceği bir satış alanı bulunmamaktadır. Çalışma alanında yapılacak düzenli ve yere özgü satış birimleri ile, hem düzensiz satışın önüne geçilmiş hem de kentsel kimlik vurgulanmış olacaktır. $\mathrm{Bu}$ sayede de yayalaştırma çalışmasının başarı ölçütleri de tamamlanacaktır.

Dünyadaki farklı yayalaştırılmış mekanlar bu çalışmada kullanılan yöntemle değerlendirilmiştir. $\mathrm{Bu}$ değerlendirme ile çalışma alanına uygulanan değerlendirme Çizelge 3'de karşılaştırılmıştır. Karşılaştırma sonucunda Lüleburgaz kent merkezinde yapılan yayalaştırma çalıştırmasının etkili bir çalışma olduğu ortadadır. Eğer bu çalışma genelinde bahsedilen eksikler de tamamlanırsa dünya çapında iyi örneklerden biri olması kaçınılmazdır.

\section{Kaynakça}

Brambilla, R. and Longo, G. (1978). For Pedestrians Only: Planning, Design and Management of Traffic-free Zones, Architect. P; New edition, 208p.

Gehl, J., Gemzøe, L., Kirknæs, S. and Sternhagen Søndergaard, B. (2006). New City Life. Arkitektens Forlag - The Danish Architectural Press, 179p. 
Giritlioğlu, C. (1991). Şehirsel Mekan Ögeleri ve Tasarımı. İ.T.Ü. Mimarlık Fak. Baskı Atölyesi, İstanbul, 179s.

Gültiken, T. (2010). Yayalaştırılmış Sokakların Kentsel Mekanda Başarısının Değerlendirilmesi İstanbul - Beyoğlu / İstiklal Caddesi Örneği. Teknik Üniversitesi, Fen Bilimleri Enstitüsü, Yüksek Lisans Tezi, 129s, İstanbul.

Keleş, R. (2021). Kentbilim Terimleri Sözlüğü 3. Basım, İmge Kitabevi Yayınları, 224s.

Moudon, A. V. (1987). Public Streets for Public Use 1st edition, Van Nostrand Reinhold, 351p.

Özmen, E. \& Kayacan, T. (2021). Kentsel Dönüşüm ve Kentsel Stres Kavramlarının Olası İlişkileri. Avrupa Bilim ve Teknoloji Dergisi, (25), 657-664.

Rapoport, A. (1987). Pedestrian Street Use: Culture and Perception. Ss 70-83. Moudon, A. V., ed., 1987. Public Streets for Public Use, VNR Company Inc. New York, 351p.

Robertson, K. A. (1994). Pedestrian Malls and Skywalks: Traffic Separation Strategies in American Downtowns. Avebury; First Edition. 156p.

Rubenstein, H. M. (1992). Pedestrian Malls, Streetscapes, and Urban Spaces, Wiley, 288p.

Vuchic, V. R. (1999). Transportation for Livable Cities. Routledge, England, 378p. 